\title{
ОСОБЕННОСТИ ИММУННОГО ОТВЕТА
}

\section{И МЕТАБОЛИЧЕСКИЕ ИЗМЕНЕНИЯ ЛИМФОЦИТОВ ПЕРИФЕРИЧЕСКОЙ КРОВИ У ДЕТЕЙ РАННЕГО ВОЗРАСТА С РЕЦИДИВИРУЮЩИМ ОБСТРУКТИВНЫМ БРОНХИТОМ}

\author{
Куртасова Л.М. ${ }^{1}$, Шакина Н.А. ${ }^{2}$ \\ ${ }_{1}^{1}$ ФГБОУ ВО «Красноярский государственный медицинский университет имени профессора В.Ф. Войно- \\ Ясенецкого» Министерства здравоохранения РФ, г. Красноярск, Россия \\ ${ }^{2}$ КГАУЗ « Красноярский краевой центр профилактики и борьбы со СПИД», г. Красноярск, Россия
}

Резюме. Цель исследования: изучение параметров Т-клеточного и гуморального иммунитета, активности НАД $(Ф)$-зависимых дегидрогеназ периферической крови у детей раннего возраста с рецидивирующим обструктивным бронхитом (РОБ). Методы: обследовано 54 ребенка в возрасте 1-3 лет с РОБ. Контрольную группу составили 35 здоровых детей аналогичного возраста. Содержание $\mathrm{CD}^{+}$, $\mathrm{CD}^{+}, \mathrm{CD}^{+}, \mathrm{CD} 19^{+}$клеток в периферической крови определяли методом проточной цитофлуориметрии. Концентрацию IgA, IgM, IgG в сыворотке крови оценивали по G. Mancini et al. (1965), ЦИКов по V. Haskova et al. (1978), общих IgE тест-системой «IgЕ общий - ИФА - Бест» (Россия). Активность НАД(Ф)-зависимых дегидрогеназ лимфоцитов периферической крови изучали биолюминесцентным методом по А.А. Савченко и соавт. (1989).

Результаты: у детей с РОБ установлены изменения фенотипического спектра лимфоцитов периферической крови, статистически значимое снижение концентрации $\operatorname{Ig}$ А и тенденция к повышению уровня IgE в сыворотке крови. Обнаружено повышение рибозо-5-фосфат и НАДФ-зависимых пластических процессов, снижение анаэробной реакции лактатдегидрогеназы, переноса продуктов липидного катаболизма на гликолиз, роли малатаспартатного шунта в энергетике клетки и активности глутатионредуктазы, повышенный уровень субстратного потока по циклу Кребса в лимфоцитах периферической крови.

Заключение: у детей раннего возраста с РОБ отмечаются изменения фенотипа и энзиматической активности лимфоцитов крови, селективный дефицит IgA в сыворотке крови.

Ключевые слова: бронхит, обструкция, рецидив, лимфоцит, фенотип, иммуноглобулины, метаболизм

\author{
Адрес для переписки: \\ Куртасова Людмила Михайловна \\ ФГБОУ ВО «Красноярский государственный медицинский \\ университет имени профессора В.Ф. Войно-Ясенецкого» \\ Министерства здравоохранения РФ \\ 660022, Россия, г. Красноярск, \\ ул. Партизана Железняка, 1. \\ Тел.: 8(391) 221-06-28.
}

Факс: 8(311) 221-16-38.

E-mail: sibmed-obozrenie@yandex.ru

\section{Образец цитирования:}

Л.М. Куртасова, Н.А. Шакина «Особенности иммунного ответа и метаболические изменения лимфоцитов периферической крови у детей раннего возраста с рещидивирующим обструктивным бронхитом» // Медицинская иммунология, 2017. Т. 19, № 5. С. 597-604. doi: 10.15789/1563-0625-2017-5-597-604

(с) Куртасова Л.М., Шакина Н.А., 2017
Address for correspondence:

Kurtasova Lyudmila M.

V.F. Voino-Yasenetsky State Medical University

660022, Russian Federation, Krasnoyarsk,

P. Zeleznyak str., 1.

Phone: 7(391) 221-06-28.

Fax: 7 (311) 221-16-38.

E-mail: sibmed-obozrenie@yandex.ru

For citation:

L.M. Kurtasova, N.A. Shakina "Features of immune response and metabolic changes in lymphocytes from peripheral blood in younger children with recurrent obstructive bronchitis ", Medical Immunology (Russia)/Meditsinskaya Immunologiya, 2017, Vol. 19, no. 5, pp. 597-604.

doi: $10.15789 / 1563-0625-2017-5-597-604$

DOI: $10.15789 / 1563-0625-2017-5-597-604$ 


\title{
FEATURES OF IMMUNE RESPONSE AND METABOLIC CHANGES IN LYMPHOCYTES FROM PERIPHERAL BLOOD IN YOUNGER CHILDREN WITH RECURRENT OBSTRUCTIVE BRONCHITIS
}

\author{
Kurtasova L.M. ${ }^{\text {, }}$, Shakina N.A. ${ }^{b}$ \\ ${ }^{a}$ V.F. Voino-Yasenetsky State Medical University, Krasnoyarsk, Russian Federation \\ ${ }^{b}$ Krasnoyarsk Regional Center for Prevention and Control of AIDS, Krasnoyarsk, Russian Federation
}

Abstract. The aim of the work was to study the parameters of T-cells, humoral immunity and activity of NAD(P)- dependent dehydrogenases in lymphocytes from peripheral blood at young children with recurrent obstructive bronchitis (ROB). Patients and Methods: Fifty-four children at the age of 1-3 years with ROB were observed. The control group consisted of 35 healthy children at similar age. The numbers of $\mathrm{CD}^{+}, \mathrm{CD}^{+}$, $\mathrm{CD}^{+}, \mathrm{CD} 19^{+}$cells in peripheral blood were determined by flow cytofluorimetric technique. IgA, IgM, and IgG concentrations in blood serum were evaluated by G. Mancini et al. (1965); circulating immune complexes (CIC), by V. Haskova et al. (1978); total IgE test was performed with "Total IgE - IFA Best" system (Russia). Relative activity of NAD (P)-dependent dehydrogenase in peripheral blood lymphocytes was studied according to A. Savchenko et al.(1989). The results of this study have revealed changed phenotypic spectrum of peripheral blood lymphocyte populations; a statistically significant reduction in IgA concentration, and a tendency for increased IgE levels in blood serum in the children with ROB. An increase of ribose-5-phosphate- and NADPdependent metabolic processes; reduced lactate dehydrogenase anaerobic reactions; a switch from lipid catabolism products to glycolysis; a shunt role of malate/aspartate in cell energy supply, and for glutathione reductase activity; elevated levels of substrate flow along Krebs cycle in peripheral blood lymphocytes were registered as well.

It may be concluded that the change of phenotype and enzymatic activity of blood lymphocytes, selective IgA deficiency in blood serum could be shown in the younger children with recurrent obstructive bronchitis.

Keywords: bronchial obstruction, bronchitis, recurrent, lymphocyte, phenotype, immunoglobulins, metabolism

Исследование выполнено при финансовой поддержке КГАУЗ «Красноярский краевой центр профилактики и борьбы со СПИД».

\section{Введение}

Заболевания органов дыхания по-прежнему остаются самой распространенной патологией у детей раннего возраста. Проблема борьбы с ними является одной из самых актуальных проблем педиатрии и практического здравоохранения.

В структуре бронхолегочной патологии среди заболеваний нижних дыхательных путей у детей раннего возраста лидирующие позиции занимает бронхит, который может проявляться обструктивным синдромом и сопровождаться рецидивами [5]. Согласно современным эпидемиологическим исследованиям, установлена тесная связь бронхита с вирусной инфекцией $[1,5]$.

Органы дыхания особенно уязвимы для вирусного поражения у детей раннего возраста из-за относительно низкой воздушной проводимости и несостоятельности местной и общей противоинфекционной защиты. Вирусная ин- фекция способна также усугублять воздействие на бронхолегочную систему обычных аэрополлютантов [6]. Частые респираторные вирусные инфекции могут приводить к деструкции эпителия дыхательных путей и усилению гипериммунной реакции с избыточным воспалительным компонентом [2].

Известно, что иммунная система - одна из важнейших гомеостатических систем организма - участвует практически во всех адаптивных реакциях. Лимфоциты, несущие рецепторы ко всем основным биологическим регуляторным веществам, отражают в известной степени общую направленность регуляторных процессов целостного организма. В то же время именно в клетке начинается формирование ответных реакций на внешнее воздействие, что позволяет составить представление об иммунологической стратегии, избранной организмом.

При этом метаболизм клетки - основа любого проявления ее жизнедеятельности, в связи с чем метаболические параметры не могут не отражать ее функциональные возможности [4]. 
Очевидно, что в качестве критерия оценки метаболической ситуации в иммунокомпетентных клетках не может быть взят какой-то один, тем более гомеостазированный, показатель.

Особенно высокой информативностью для исследования метаболизма лимфоцитов, основного структурно-функционального элемента иммунной системы, обладают окислительно-восстановительные ферменты. Это связано с тем, что, являясь основными переносчиками электронов в клетке, они осуществляют ключевые реакции клеточного метаболизма и участвуют в направленной координации сопряженных метаболических потоков [4].

В связи с вышеизложенным целью исследования явилось изучение параметров Т-клеточного и гуморального иммунитета, активности НАДи НАДФ-зависимых дегидрогеназ лимфоцитов периферической крови у детей раннего возраста с рецидивирующим обструктивным бронхитом.

\section{Материалы и методы}

Проведено открытое клиническое исследование.

Критериями включения в исследование являлись: возраст 1-3 года; европеоидная раса; бронхит с бронхообструктивным синдромом, рецидивирующее течение; отсутствие хронических очагов инфекции; отсутствие терапии в течение месяца, предшествующего обследованию.

Критерии исключения из исследования:

- простой бронхит;

- бронхиальная астма;

- наличие сопутствующих заболеваний (наследственных и врожденных).

Исследования проводили на базе Красноярского краевого Центра профилактики и борьбы со СПИД. Обследовано 54 ребенка в возрасте от одного года до трех лет (средний возраст $2,09 \pm 0,83$ года), из них $30(55,56 \%)$ мальчиков и 24 девочки $(44,44 \%)$. Диагноз: обструктивный бронхит, рецидивирующее течение, был верифицирован на основании жалоб, клинической картины (кашель спастического характера, повышение температуры, затрудненное дыхание с удлиненным продолжительным выдохом, перкуторно легочный звук с коробочным оттенком, при аускультации жесткое дыхание, нарушение фаз дыхательного цикла с преобладанием фазы выдоха, сухие рассеянные, свистящие хрипы) и рентгенологического обследования органов грудной клетки (отсутствие очаговых и инфильтративных теней, эмфизематозность легочных полей). У наблюдаемых детей отмечалось до 3 эпизодов бронхообструктивного синдрома на фоне острой респираторной инфекции. Сенсибилизации к пищевым, бытовым, эпидермаль- ным и пыльцевым аллергенам не обнаружено. В назоцитограммах среди клеточных элементов превалировали лимфоциты, содержание эозинофилов - 0-1-2 в поле зрения.

Контрольную группу составили 35 здоровых детей в возрасте 1-3 лет (средний возраст $2,14 \pm 0,84$ года), из них $19(54,29 \%)$ мальчиков и $16(45,71 \%)$ девочек.

Мононуклеары выделяли из цельной гепаринизированной крови центрифугированием в градиенте плотности фиколл-верографина

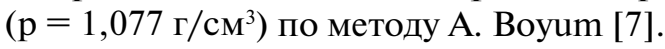

При контроле морфологического состава лейкоцитарной взвеси определялась чистота выхода лимфоцитов, составляющая не менее $97 \%$. Для биолюминесцентного анализа использовали 1 млн выделенных лимфоцитов.

Суспензию выделенных лимфоцитов, содержащую клетки в концентрации 1 млн/мл, после однократного замораживания-размораживания дополнительно разрушали путем осмотического лизиса с добавлением 2,0 мМ дитиотреитола. Затем осуществляли биолюминесцентное определение активности глюкозо6-фосфатдегидрогеназы (ГбФДГ, КФ1.1.1.49), глицерол-3-фосфатдегидрогеназы (ГЗФДГ, КФ1.1.1.8, НАД- и НАДФН-зависимой лактатдегидрогеназы (НАДЛДГ, НАДНЛДГ, КФ1.1.1.27), НАД- и НАДН-зависимой малатдегидрогеназы (НАДМДГ, НАДНМДГ, КФ1.1.1.37), НАД- и НАДН-зависимой глутаматдегидрогеназы (НАДГДГ, НАДНГДГ, КФ 1.4.1.2), НАДФ- и НАДФН-зависимой глутаматдегидрогеназы (НАДФГДГ, НАДФНГДГ, КФ1.4.1.4), НАД-зависимой изоцитратдегидрогеназы (НАДИЦДГ, КФ 1.1.1.41) НАДФ-зависимой изоцитратдегидрогеназы (НАДФИЦДГ, КФ1.1.1.42), малатдегидрогеназы декарбоксилирующей (НАДФМДГ, КФ1.1.1.40) и глутатионредуктазы (ГР, КФ1.6.4.2). Активность НАДЛДГ, НАДМДГ, НАДГДГ, НАДФГДГ определяли как по прямым, так и по обратным реакциям (НАДНЛДГ, НАДНМДГ, НАДНГДГ, НАДФНГДГ соответственно). Для этого к 150 мкл инкубационной смеси разрушенных лимфоцитов (концентрация субстратов и кофакторов), а также $\mathrm{pH}$ среды соответствуют величинам, указанным в используемой нами методике А.А. Савченко, Л.Н. Сунцовой [3].

В инкубационную смесь для определения активности НАДФИЦДГ и НАДИЦДГ дополнительно добавляли аденозинфосфат (Applichem GMBH, Германия) в концентрациях 2,15 и 1,3 мМ соответственно). В среду инкубации для определения уровней НАДНГДГ и НАДФНГДГ дополнительно вносили $\mathrm{NH} 4 \mathrm{Cl}$ (Sigma,США) в концентрации 5,0 мМ, а для определения ГРЭДТА (Sigma,США) в концентрации 0,5 мМ. После инкубации исследуемых проб при $37^{\circ} \mathrm{C}$ 
в течение 30 мин (для ферментативных реакций с восстановленным НАД $(Ф)+)$ или 5 мин (для реакций с окислением НАД(Ф)Н) к 200 мкЛ инкубационной смеси добавляли 50 мкл флавинмононуклеотида (FMN, Applichem GMBH, Германия) в концентрации 1,5 × $10^{-5} \mathrm{M}, 50$ мкл 0,0005\% миристинового альдегида (Sigma, США) и 10 мкл ферментативной системы НАД(Ф) H:FMN оксидоредуктаза-люцифераза (все реактивы биолюминесцентной системы разведены в $0,1 \mathrm{M} \mathrm{K}^{+}, \mathrm{NA}^{+}$-фосфатном буфере (Реахим, Россия) с рН 7,0. Ферментативная система НАД(Ф) H:FMN оксидоредуктаза-люцифераза изготовлена из очищенных методами ионообменной хроматографии и гель-фильтрации люциферазы из Photobacterium legionathi и оксиредуктазы из Vibrio fischeri в Институте биофизики СО РАН, г. Красноярск.

После смешивания биолюминесцентных реактивов и инкубационной пробы с помощью биолюминометра «БЛМ-8801» (Россия) осуществляли измерение свечения. Активность исследуемых оксидоредуктаз выражали в ферментативных единицах (1E = 1мкмоль/мин) на $10^{4}$ клеток. Для проведения биолюминесцентного анализа также использовали глюкозо-6-фосфат, глицерол-3-фосфат, лактат, малат (Sigma, США), глутамат, изоцитрат, 2-оксоглутарат, пируват, оKсалоацетат (ICN Biomedicals Inc., США), глутатион окисленный, НАД ${ }^{+}$, НАДФ, НАДН и НАДФН (Applichem GMBН, Германия).

Методом проточной цитофлуориметрии с использованием прибора "FACS Callibur" (Becton Dickinson, США) и реагентов "Simultesf IMKlymphocyte Kit" (США) определяли содержание $\mathrm{CD}^{+}, \mathrm{CD}^{+}, \mathrm{CD}^{+}, \mathrm{CD} 19^{+}$клеток в периферической крови.

Концентрацию иммуноглобулинов классов А, M, G в сыворотке крови оценивали методом радиальной иммунодиффузии в геле [13]. Содержание циркулирующих иммунных комплексов (ЦИК) в сыворотке крови исследовали в реакции с полиэтиленгликолем [10]. Концентрацию иммуноглобулинов класса Е в сыворотке крови определяли методом иммуноферментного анализа тест-системой «IgЕ общий-ИФА -Бест» (Россия).

Исследование одобрено Локальным этическим комитетом Красноярского государственного медицинского университета им. проф. В.Ф. Войно-Ясенецкого (протокол № 23/2011 от 02 апреля 2011 г.).

\section{Статистический анализ}

Статистическая обработка данных проводилась с использованием программы Statistica v. 6.0 (StatSoft Ins., США).

Нормальность распределения показателей определялась с помощью метода Колмогорова-Смирнова. Количественные показатели, учитывая нормальное распределение, описывались с использованием средних арифметических значений (М) и стандартной ошибки среднего $( \pm \mathrm{m})$. Для изучения статистической значимости различий между количественными признаками представленных групп применяли t-критерий Стьюдента. Критический уровень значимости (p) при проверке статистических гипотез принимали равным 0,05. При этом значение р могли ранжировать по трем уровням достигнутых статически значимых различий: $\mathrm{p}<0,05 ; \mathrm{p}<0,01 ; \mathrm{p}<0,001$.

\section{Результаты}

Анализ полученных данных выявил в группе детей с РОБ выраженную тенденцию к повышению количества лейкоцитов и статистически значимое увеличение абсолютного числа лимфоцитов периферической крови по сравнению с параметрами контрольной группы (табл. 1).

При изучении фенотипического спектра лимфоцитов периферической крови в исследуемой группе детей с РОБ обнаружили статистически значимое увеличение абсолютного числа зрелых Т-лимфоцитов $\left(\mathrm{CD}^{+}\right)$и $\mathrm{CD}^{+}$клеток, а также на фоне процентного снижения количества $\mathrm{CD}_{4}{ }^{+}$ клеток выраженную тенденцию к повышению процентного содержания $\mathrm{CD}^{+}$клеток в периферической крови относительно показателей группы контроля (табл. 1). Абсолютное и относительное количество В-лимфоцитов в периферической крови в группе детей с РОБ статистически значимо не отличалось от аналогичных показателей контрольной группы (табл. 1).

Реакция гуморального звена иммунитета характеризовалась снижением в 1,47 раза ( $>$ < 0001) концентрации иммуноглобулинов класса А и тенденцией к повышению уровня общих IgE в сыворотке крови в группе больных с РОБ $(0,1>$ p $>0,05)$ по сравнению с параметрами контроля (табл. 1).

Результаты исследования активности НАД(Ф)-зависимых дегидрогеназ в лимфоцитах периферической крови установили повышение активности ГбФДГ в группе детей с РОБ относительно контрольных значений (рис. 1В).

Изучение активности исследуемых оксидоредуктаз митохондриального компартмента лимфоцитов крови позволило констатировать в группе детей с РОБ статистически значимое увеличение активности НАДИЦДГ и НАДМДГ, а также вспомогательной реакции НАДФИЦДГ на фоне снижения в 6,07 раза $(\mathrm{p}<0,001)$ уровня активности малик - фермента (рис. 1Б, В). Следует отметить повышение активности НАДГДГ по прямой и снижение НАДГДГ и НАДФГДГ по обратной реакциям по сравнению с показателями контрольной группы (рис. 1А). 


\section{ТАБЛИЦА 1. ИММУНОЛОГИЧЕСКИЕ ПОКАЗАТЕЛИ У ДЕТЕЙ С РЕЦИДИВИРУЮЩИМ ОБСТРУКТИВНЫМ

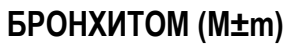

TABLE 1. IMMUNOLOGICAL INDEXEX FOR CHILDREN WITH A RECRUDESCENT OBSTRUCTIVE BRONCHITIS (M $\pm m$ )

\begin{tabular}{|c|c|c|c|}
\hline $\begin{array}{l}\text { Показатель } \\
\text { Index }\end{array}$ & $\begin{array}{c}\text { Контрольная группа } \\
\text { Control group } \\
(\mathbf{n}=35) \\
\end{array}$ & $\begin{array}{c}\text { Больные дети } \\
\text { Sick children } \\
(\mathbf{n}=54) \\
\end{array}$ & $\mathbf{p}$ \\
\hline $\begin{array}{l}\text { Лейкоциты, } 10^{9} / л \\
\text { Leucocytes, 109/L }\end{array}$ & $8,42 \pm 0,15$ & $9,64 \pm 0,67$ & $0,1>p>0,05$ \\
\hline $\begin{array}{l}\text { Лимфоциты, \% } \\
\text { Lymphocytes, \% }\end{array}$ & $45,10 \pm 1,49$ & $49,30 \pm 2,84$ & \\
\hline $\begin{array}{l}\text { Лимфоциты, 10\%/л } \\
\text { Lymphocytes, 10\%/L }\end{array}$ & $3,43 \pm 0,11$ & $4,74 \pm 0,40$ & $<0,002$ \\
\hline $\begin{array}{l}\text { CD3 }^{+} \text {клетки, \% } \\
\text { CD3 }^{+} \text {cell, \% }\end{array}$ & $61,90 \pm 2,11$ & $59,61 \pm 1,52$ & \\
\hline $\begin{array}{l}\text { CD3 }^{+} \text {клетки, 109/л } \\
\text { CD3 }^{+} \text {cell, } 10^{9} / \mathrm{L}\end{array}$ & $2,10 \pm 0,05$ & $2,80 \pm 0,25$ & $<0,01$ \\
\hline $\begin{array}{l}\text { CD4 }^{+} \text {клетки, \% } \\
\text { CD4 }{ }^{+} \text {cell, \% }\end{array}$ & $36,07 \pm 1,94$ & $29,32 \pm 0,88$ & $<0,01$ \\
\hline $\begin{array}{l}\text { CD4 }^{+} \text {клетки, } 10^{9} / л \\
\text { CD4 }{ }^{+} \text {cell, } 10^{9} / \mathrm{L}\end{array}$ & $1,52 \pm 0,07$ & $1,71 \pm 0,14$ & \\
\hline $\begin{array}{l}\text { CD8 }^{+} \text {клетки, \% } \\
\text { CD8 }{ }^{+} \text {cell, \% }\end{array}$ & $16,21 \pm 1,35$ & $20,40 \pm 2,11$ & $0,1>p>0,05$ \\
\hline $\begin{array}{l}\text { CD8 }^{+} \text {клеток, } 10^{9} / л \\
\text { CD8 }{ }^{+} \text {cell, } 10^{9} / \mathrm{L}\end{array}$ & $0,54 \pm 0,04$ & $0,93 \pm 0,12$ & $p<0,01$ \\
\hline $\mathrm{CD}^{+} / \mathrm{CD} 8$ & $2,92 \pm 0,19$ & $2,26 \pm 0,25$ & $p<0,05$ \\
\hline $\begin{array}{l}\text { CD19+ клетки, \% } \\
\text { CD19+ cell, \% }\end{array}$ & $11,45 \pm 1,13$ & $12,00 \pm 1,21$ & \\
\hline $\begin{array}{l}\text { CD19+ клетки, 109/л } \\
\text { CD19+ cell, 10\%/L }\end{array}$ & $0,38 \pm 0,04$ & $0,47 \pm 0,04$ & \\
\hline $\begin{array}{l}\lg A, \text { г/л } \\
\lg A, g / l\end{array}$ & $0,87 \pm 0,06$ & $0,59 \pm 0,04$ & $<0,001$ \\
\hline $\begin{array}{l}\lg M, r / ת \\
\lg M, g / l\end{array}$ & $0,62 \pm 0,05$ & $0,71 \pm 0,04$ & \\
\hline $\begin{array}{l}\lg G, \text { г/л } \\
\lg G, g / l\end{array}$ & $6,95 \pm 0,49$ & $7,24 \pm 0,46$ & \\
\hline $\begin{array}{l}\operatorname{lgE}, \text { МЕ/мл } \\
\operatorname{lgE}, \mathrm{ME} / \mathrm{ml}\end{array}$ & $17,45 \pm 1,68$ & $23,16 \pm 2,38$ & $0,1>p>0,05$ \\
\hline $\begin{array}{l}\text { ЦИК, o.e. } \\
\text { CІC, s.u. }\end{array}$ & $42,06 \pm 2,32$ & $45,50 \pm 4,71$ & \\
\hline
\end{tabular}

Примечание. p - статистически значимые различия с показателями контрольной группы.

Note. p, statistically meaningful distinctions with the indexes of control group.

Кроме того, в группе детей с РОБ в лимфоцитах периферической крови снижена анаэробная реакция ЛДГ, а также в 5,82 раза $(\mathrm{p}<0,001)$ активность ГЗФДГ, в 13,17 раза $(\mathrm{p}<0,001)$ НАДНМДГ и в 7,23 раза $(\mathrm{p}<0,001)$ понижается уровень ГР относительно контрольных параметров (рис. 1Б, В).

\section{Обсуждение}

Исследуемые нами ферменты занимают ключевые позиции на разных метаболических путях клетки. Так, снижение активности анаэробной реакции ЛДГ и НАДН-зависимой реакции МДГ в лимфоцитах крови в группе детей с РОБ может отражать низкую активность анаэробного окисления глюкозы и, соответственно, пониженный уровень наработки НАДН в гликолизе. Снижение интенсивности анаэробного окисления глюкозы может быть компенсировано повышением активности ГЗФДГ-фермента, осуществляющего перенос продуктов липидного катаболизма на окислительно-восстановительные реакции гликолиза [8]. Однако активность данного энзима в лимфоцитах периферической крови в группе детей с РОБ значительно снижена.

Состояние митохондриального компартмента лимфоцитов периферической крови в группе детей с РОБ характеризуется повышением уровня 
$A(A)$

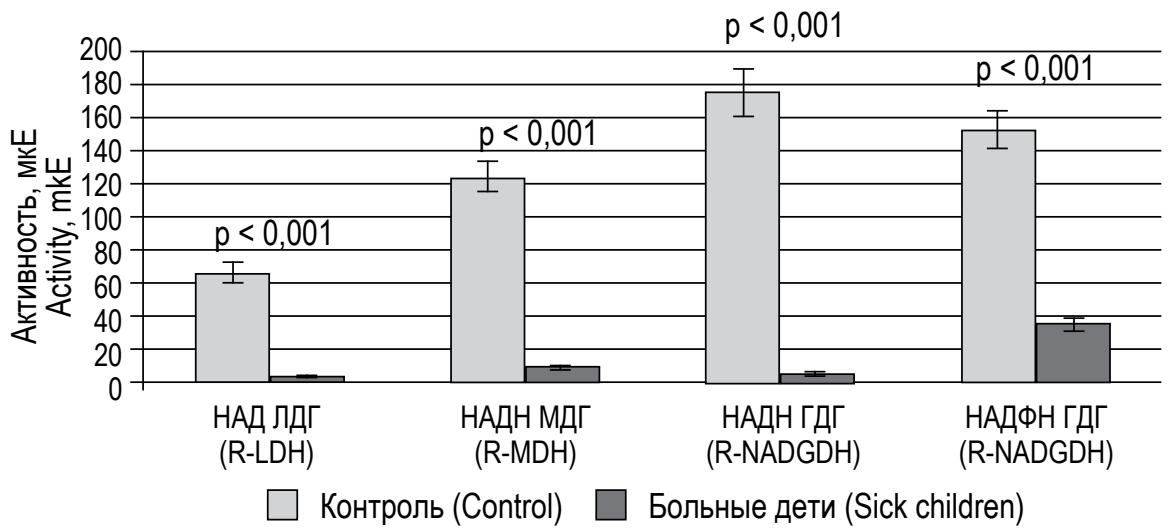

$5(B)$

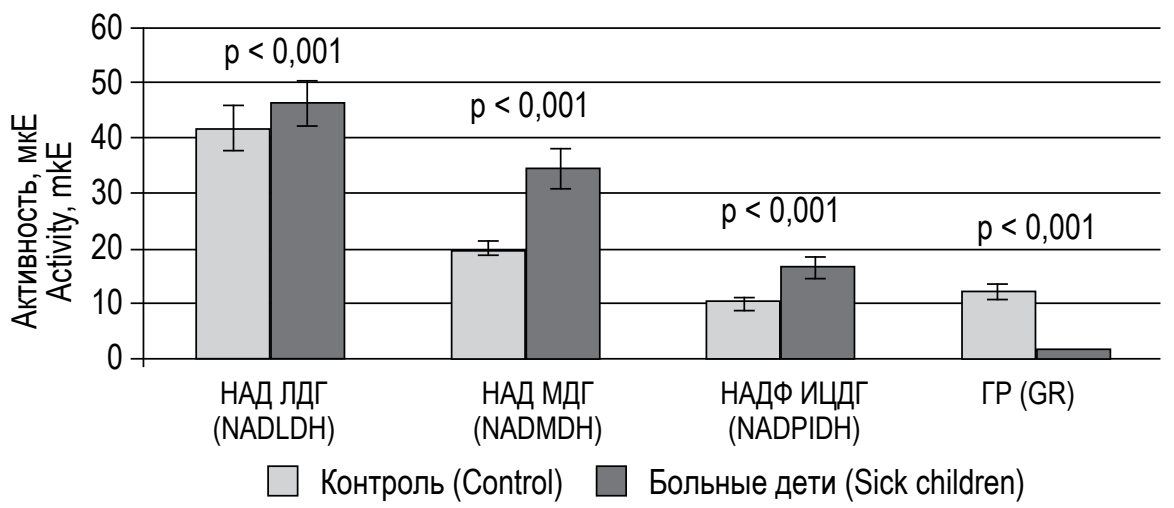

$B(C)$

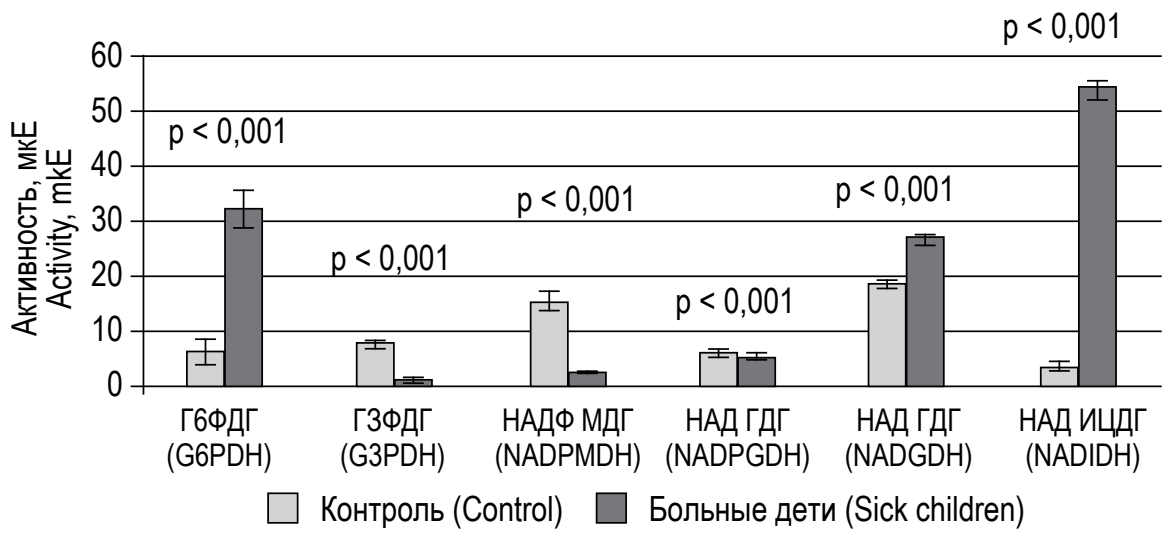

Рисунок 1. Показатели активности НАД(Ф)-зависимых дегидрогеназ в лимфоцитах периферической крови у детей с рецидивирующим обструктивным бронхитом

Примечание. p - статистически значимые различия с показателями контрольной группы.

Figure 1. Activity of NAD (P)-dependent dehydrogenases from peripheral blood lymphocytes in children with recurrent obstructive bronchitis

Note. p, statistically significant differences from the control group.

НАДМДГ, НАДИЦДГ и НАДФИЦДГ, что отражает увеличение субстратного потока как на начальных реакциях, так и терминальных стадиях цикла Кребса.

Необходимо отметить в лимфоцитах крови в группе детей с РОБ повышение активности НАДГДГ, что свидетельствует о субстратной стимуляции лимонного цикла продуктами реакций аминокислотного обмена $[12,15]$.
В то же время отмечается пониженная активНость НАДНГДГ и НАДФНГДГ в лимфоцитах периферической крови в группе больных с РОБ. По-видимому, высокая интенсивность работы дыхательной цепи и НАД-зависимых дегидрогеназ цикла трикарбоновых кислот ограничивают возможность использования НАДНГДГ и НАДФНГДГ для стимуляции реакций аминокислотного обмена. 
В лимфоцитах периферической крови в группе детей с РОБ наблюдается повышение активности ГбФДГ, характеризующее интенсификацию пластических процессов, зависящих от продуктов пентозофосфастного цикла $[14,16]$. При этом увеличение оттока интермедиатов на реакции пластического обмена вызывает снижение интенсивности субстратного потока по гликолизу, что выражается в пониженном уровне анаэробной реакции ЛДГ в лимфоцитах крови в группе детей с РОБ.

Кроме того, в лимфоцитах крови в группе детей с РОБ отмечается низкая активность маликфермента (НАДФМДГ). Роль данного фермента в клеточном метаболизме определяется, прежде всего, восстановлением НАДФ до НАДФН, который затем используется в синтетических клеточных процессах $[11,18]$. Снижение активности НАДФМДГ может приводить к недостаточному образованию восстановительной формы цитоплазматического НАДФН и недостатку субстратов для биосинтеза жирных кислот, а это может определять снижение реакций липидного обмена в клетке. В связи с этим можно заключить, что если на уровень митохондриального обмена в лимфоцитах крови в группе детей с РОБ сниженная активность малик-фермента не оказывает значимого влияния, то ингибирование ГЗФДГ может быть связано с понижением реакций липидного анаболизма.

Глутатионредуктаза осуществляет восстановление глутатиона за счет окисления НАДФН, что определяет его функциональную важность в реакциях глутатион-зависимой антиоксидантной системы $[9,17]$. Сниженная активность ГР в лимфоцитах периферической крови в группе детей с РОБ может привести к снижению антиоксидантной защиты клетки.

Следовательно, у детей с РОБ в период клинической ремиссии сохраняются метаболические нарушения в лимфоцитах крови, что, учитывая, высокую значимость метаболических реакций для функциональной активности клетки, может явиться одной из возможных причин, способствующих рецидиву заболевания. Данное обстоятельство диктует необходимость проведения метаболической реабилитации, направленной на восстановление внутриклеточных обменных процессов в клетках иммунной системы.

\section{Заключение}

Результаты проведенного исследования выявили у детей с РОБ на фоне увеличения абсолютного числа лимфоцитов периферической крови изменения их фенотипического спектра, а также снижение уровня IgA и тенденцию к повышению концентрации IgE в сыворотке крови.

Полученные нами данные обнаружили в лимфоцитах периферической крови у детей с РОБ повышенный отток субстратов через ГбФДГ на пластические процессы и снижение интенсивности реакций гликолиза на терминальных стадиях, а также понижение субстратного питания за счет продуктов липидного обмена.

В лимфоцитах периферической крови у детей с РОБ наблюдается высокий уровень субстратного потока по циклу Кребса, вносящему наибольший вклад в процессы клеточного энергообразования. В то же время определяется значительное снижение оттока субстратов через НАДНГДГ и НАДФНГДГ с цикла трикарбоновых кислот на реакции аминокислотного обмена. Кроме того, установлено снижение активности глутатионредуктазы, что может способствовать повышению интенсивности перекисных процессов в клетке.

\section{Конфликт интересов}

Авторы статьи подтверждают отсутствие финансовой поддержки/конфликта интересов, о которых необходимо сообщить.

\section{Список литературы / References}

1. Борисенко Г.Н., Носуля Е.В., Никулин И.В. Клинико-эпидемиологические аспекты заболевания верхних дыхательных путей у детей с рецидивирующей респираторной инфекцией // Российская ринология, 2012. Т. 22, № 4. C. 38-42. [Borisenko G.N., Nosulya E.V., Nikulin I.V. Upper respiratory tract diseases in children with recurrent respiratory infection. Rossiyskaya rinologiya $=$ Russian Rhinology, 2012, Vol. 22, no. 4, pp. 38-42. (In Russ.)]

2. Караулов А.В. Иммуномодуляция при респираторных инфекциях: от понимания целей и механизмов действия к клинической эффективности // Детские инфекции, 2012. № 3. C. 62-64. [Karaulov A.V. Immunomodulation in therapy of respiratory infections: from understanding of the goals and mechanisms of action to clinical efficiency. Detskie infektsii = Children's Infections, 2012, no. 3, pp. 62-64. (In Russ.)]

3. Савченко А.А., Сунцова Л.Н. Высокочувствительное определение активности дегидрогеназ в лимфоцитах периферической крови биолюминесцентным методом // Лабораторное дело, 1989. № 11. С. $23-25$. [Savchenko A.A., Suntsova L.N. Higly sensitive determination of the dehydrogenase activity in peripheral bloodlymphocytes using a bioluminescent method. Laboratornoe delo = Laboratory Case, 1989, no. 11, pp. $23-25$. (In Russ.)] 
4. Савченко А.А., Борисов А.Г. Основы клинической иммунометаболомики. Новосибирск: Наука, 2012. 263 c. [Savchenko A.A., Borisov A.G. Basis of the Clinical immunometabolomic]. Novosibirsk: Science, 2012. $263 \mathrm{p}$.

5. Сорока Н.Д. Острый бронхит у детей: состояние проблемы, актуальные пути решения // Педиатрия, 2013. T. 92, № 6. C. 106-114. [Soroka N.D. Acute bronchitis in children: the problem, actual solutions. Pediatriya $=$ Pediatrics, 2013, Vol. 92, no. 6, pp. 106-114. (In Russ.)]

6. Юренев Г.Л., Юренева-Тхоржевская Т.В. Бронхообструктивный синдром при острых респираторных вирусных инфекциях: причины и последствия // Практическая пульмонология, 2014. № 1. С. 1-7. [Yurenev G.L., Yureneva-Thorzhevskaya T.V. Bronchial obstruction syndrome with acute respiratory virus infections: the causes and consequences. Prakticheskaya pulmonologiya = Practical Pulmonology, 2014, no. 1, pp. 1-7. (In Russ.)]

7. Boyum A. Isolation of lymphocytes from blood and bone marrow. Scand. Clin. Lab. Invest, 1968, Vol. 21, no. 97, pp. $77-80$.

8. DeLa Roche M., Tessier S.N., Storey K.B. Structural and functional properties of glycerol-3-phosphate degydrogenase from a mammalian hibernator. Protein J., 2012, Vol. 31, no. 2, pp. 109-119.

9. Diukic M.M., Jovanovic M.D., Ninkovic M., Stevanovic I., Ilic K. Curcic M., Vekic J. Protective role of glutatione reductase in paraquat induced neurotoxicity. Chem. Biol. Interact., 2012, Vol. 199, no. 2, pp. 74-86.

10. Haskova V., Kaslik J., Rina J., Rovensky J. Simple method of circulating immune complex detection in human sera by polyethylene glycol precipitation. J. Immunol., 1978, Vol. 154, pp. 399-406.

11. Hsieh J.Y., Chen S.H., Hung H.C. Functional roles of the tetramer organization of malic enzyme. J. Biol. Chem., 2009, Vol. 284, no. 27, pp. 18096-18105.

12. Li M., Li C., Allen A., Stanley C.A., Smith T.J. The structure and allosteric regulation of mammalian glutamate dehydrogenase. Arch. Biochem. Biophys., 2012, Vol. 519, no. 2, pp. 69-80.

13. Mancini G., Carbanaro A.O., Haremans J.F. Immunochemical quantitation of antigens by single radial diffusion. Immunochemistry, 1965, Vol. 2, no. 3, pp. 235-255.

14. Norris M.G., Malys N. What is the true enzyme kinetics in the biological system? An investigation of macromolecular crowding effect upon enzyme kinetics of glucose-6-phosphate dehydrogenase. Biochem. Biophys. Res. Commun, 2011, Vol. 405, no. 3, pp. 388-392.

15. Spanaki C., Plaitakis A. The role of glutamate dehydrogenase in mammalian ammonia metabolism. Neurotox. Res, 2012, Vol. 21, no. 1, pp. 117-127.

16. Stanton R.C. Glucose-6-phosphate dehydrogenase, NADPH, and cell survival. IUBMB Life, 2012, Vol. 64, no. 5, pp. 362-369.

17. Tandogan B., Sengezer C., Ulusu N.N. In vitro effects of imatinib on glucose-6-phophate degydrogenase and glutathione reductase. Folia Biol. (Praha), 2011, Vol. 57, no. 2, pp. 57-64.

18. Wand B., Wang P., Zhend E., Chen X., Zhao H., Song P., Su R., Li X., Zhu G. Biochemical properties and physiological roles of NADP - dependent malic enzyme in Escherichia coli. J. Microbiol, 2012, Vol. 49, no. 5, pp. 797-802.

\section{Авторы:}

Куртасова Л.М. - д.м.н., профессор кафедры клинической иммунологии ФГБОУ ВО «Красноярский государственный медицинский университет имени профессора В.Ф. Войно-Ясенецкого» Министерства здравоохранения РФ, г. Красноярск, Россия

Шакина Н.А. - к.м.н., врач клинической лабораторной диагностики лаборатории иммунологических и гематологических исследований КГАУЗ « Красноярский краевой центр профилактики и борьбы со СПИД», г. Красноярск, Россия
Authors:

Kurtasova L.M., PhD, MD (Medicine), Professor, Department of Clinical Immunology, V.F. Voino-Yasenetsky State Medical University, Krasnoyarsk, Russian Federation

Shakina N.A., PhD (Medicine), Doctor, Laboratory of Immunological and Haematological Research, Krasnoyarsk Regional Center for Prevention and Control of AIDS, Krasnoyarsk, Russian Federation 